\title{
Direitos Humanos em Rede Limites Estruturais à Cidadania de Máxima Inclusão no uso de Tecnologias de Informação e Comunicação no Interior Brasileiro em Processo Social de Transição
}

\author{
Luciano Miranda \\ Professor-adjunto da Universidade Federal de Santa Maria \\ (UFSM). Doutor em Ciência Política pela Universidade \\ Federal do Rio Grande do Sul (UFRGS). Líder do Núcleo \\ de Análise das Variações na Economia Política dos Direi- \\ tos Fundamentais - Direito no Espaço Transnacional de \\ Relações Jurídicas (navE-DETReJ) - Grupo de pesquisa \\ CNPq. lucmira.ufsm@gmail.com.
}

\section{Resumo:}

0 artigo problematiza os limites estruturais à efetivação dos direitos humanos em rede, entendidos como a condição de possibilidade a cidadania de máxima inclusão no uso das tecnologias de informação e comunicação, em Frederico Westphalen-RS, cujo processo social de transição é evidente. Para tanto, analisa dados coletados em pesquisa que enfocou principalmente as práticas culturais da comunidade escolar do município. Conclui-se que falta interação entre a esfera de poder municipal e 0 governo federal, há exigência da superação dos limites socioculturais, institucionais e disposicionais e deve ser priorizada a educação básica das crianças e suas famílias em consonância à diversidade e à complexidade do mundo contemporâneo.

Palavras-chave: Cidadania. Direitos em rede. Frederico Westphalen. Inclusão Digital. TICs. 


\title{
HUMAN RIGHTS AT THE WEB: Structural limits to the citizenship of maximum inclusion in information and communication technology use in the Brazilian interior under social transition process
}

\begin{abstract}
:
The article discusses the structural limits for enforcing network human rights, understood as the condition of possibility to maximum inclusion citizenship toward the uses of information and communication technologies, in Frederico Westphalen, which presents social process of evident transition. It analyzes data collected in research that mainly focused on the cultural practices of the school community in the city. It concludes that interaction between the sphere of municipal power and the Federal Government is rare, there is requirement of overcoming the socio-cultural, institutional and dispositional limits and should be prioritized basic education of children and their families in line to the diversity and the complexity of the contemporary world.
\end{abstract}

Keywords: Citizenship. Digital Divide. Frederico Westphalen. ICTs. Network Rights.

\section{SUMÁRIO}

1 Introdução. 2 Limite Sociocultural. 3 Limite Institucional. 4 Limite Disposicional. 5 Considerações Finais: Efetivação de Direitos para a Educação (Digital). 6 Referências 


\section{INTRODUÇÃO}

$\mathrm{O}$ acesso às Tecnologias de Informação e Comunicação (TICs), entendido como a efetividade de direitos aos cidadãos, especialmente da internet, é etapa em que os indivíduos e os coletivos - ora delas "usuários" - podem, por meio da apropriação de capital informacional e do conhecimento, obstaculizar processos de exclusão social e, destarte, reforçar a democracia e a justiça social. Mesmo que os conceitos em circulação no campo acadêmico gerem questionamentos e embates intelectuais pelo sentido específico de suas definições, a importância do estudo dos direitos humanos em rede se estabelece com relativo consenso, quer sejam enfocados como "direitos virtuais", ${ }^{1}$ como observância da existência dos pressupostos da inclusão, da transparência e da universalidade no "espaço público on-line", ${ }^{2}$ ou ainda, simplesmente como planejamento e execução de políticas públicas de "inclusão digital”3 que a valoriza sem afastar a criticidade. Por efeito, a abordagem da inclusão digital como objeto de estudo dos direitos humanos em rede acarreta a incorporação de dimensões outras além daquela do acesso aos meios.

Assim considerado, o trabalho questiona os limites estruturais da inclusão digital na acepção da cidadania de máxima inclusão ${ }^{4}$ ao uso das TICs em região periférica do interior brasileiro, com infraestrutura de redes telemáticas subdesenvolvida ou subutilizada e “administradas" por agentes políticos (ora considerados gestores e mandatários de cargos

${ }^{1}$ Cf. Wolkmer (2010, p. 21): "Os direitos virtuais são os direitos advindos das tecnologias de informação (Internet), do ciberespaço e da realidade virtual em geral.”

2 Oliveira; Rodegheri (2014).

${ }^{3}$ Ver em especial Cazeloto (2008).

${ }^{4}$ Mendonça (2012). A “cidadania de máxima inclusão" deve ser compreendida como norma ético-jurídica e princípio constitucional (Cf., em especial, o artigo $1^{\circ}$, II, da Constituição da República), isto é, mandamento de otimização tal como propõe Alexy (2008). Deve ser observada, enquanto princípio em toda atividade estatal, inclusive jurisdicional, ao dizer o direito, que tem o dever de lhe observar. 
públicos, educadores e líderes comunitários) os quais não contam ou muito pouco contam com a hipótese dessa acepção no seu escopo de possíveis decisões à execução de políticas públicas. Especificamente, o corpus da pesquisa encontra-se em Frederico Westphalen-RS, município do interior brasileiro em processo de acelerada transição social, no sentido de Tönnies, da Gemeinschaft à Gesellschaft. ${ }^{5} \mathrm{Na}$ comunidade, constituída por agrupamentos relativamente pequenos e pré-industriais, a base comunitária é fortemente coesa surgida do parentesco, práticas sociais herdadas dos antepassados e a união do grupo mediante profundos sentimentos religiosos. Por outro lado, na sociedade aparece vida urbana desenvolvida, divisão do trabalho social e maior integração com o Estado. No município em foco, esse processo social de "transição modernizadora" se deve em muito à concentração no município de autarquias e órgãos públicos que atraem imigrantes, tanto nacionais quanto estrangeiros, contribuindo ao incremento da economia local sem necessariamente lograrem romper com a impermeabilidade cultural nativa. Esse fenômeno é, em parte, compreendido na medida em que são constatados limites estruturais para a substantiva efetivação de direitos. Essa constatação resulta de projeto de pesquisa $^{6}$ que se desdobra em diferentes subprojetos.

${ }^{5}$ Comunidade e Sociedade, respectivamente, embora a simples tradução dos vocábulos não logra dar conta dos complexos processos sociais subjacentes aos conceitos. Cf. Buber (2008).

${ }^{6}$ Miranda (2014). Para o cálculo da amostra, realizou-se estratificação em dois níveis: $1^{0}$ ) por semelhança da população; subconjuntos de funcionários (técnicos em administração escolar), de professores e de cada série/ano dos estudantes; $2^{\circ}$ ) por turmas dentro de cada escola, no caso dos estudantes, e por classe de funcionários ou professores em cada escola, no caso de servidores. Têm-se, assim, os seguintes resultados: da população de 685 servidores (professores e funcionários) e 4.818 estudantes, calculou-se a amostra de acordo com a fórmula utilizada em survey para populações finitas (menores que $100 \mathrm{mil}$ ): $\mathrm{n}=\sigma^{2} \cdot \mathrm{p} \cdot \mathrm{q} \cdot \mathrm{N}$

$\overline{\mathrm{e}^{2}(\mathrm{~N}-1)+\sigma^{2} \cdot \mathrm{p} \cdot \mathrm{q}}$

Em que: $\mathrm{N}$ = população; $\mathrm{n}$ = amostra; $\sigma$ = nível de confiança em desvios padrão; $\mathrm{e}=$ margem de erro; $\mathrm{p}=\%$ com a qual o fenômeno se verifica; $\mathrm{q}=\%$ complementar. Cf. Babbie (2001). Ao todo, foram entrevistados 353 integrantes da comunidade escolar de Frederico Westphalen. A fim de viabilizar a adoção de diferentes métodos de coleta de dados, foi 
Em razão das limitações à redação, aqui são destacados três desses limites estruturais, assim denominados: sociocultural; institucional e disposicional. A classificação desempenha papel de sistematização. Não é estanque. Ao contrário, os limites se inter-relacionam continuamente em uma dinâmica social que se transforma na medida em que a sociedade também se transforma. Dessa inter-relação, é privilegiado o espaço escolar como ambiente em que se entrecruzam e em que são observáveis efeitos colaterais indesejados para os quais a ciência jurídica comprometida com o aprimoramento da cidadania ${ }^{7}$ pode - e deve - apresentar proposições como contribuição a partir dos resultados da análise social.

\section{LIMITE SOCIOCULTURAL}

A sociedade da informação, de modo mais apropriado sociedade do conhecimento, apresenta um potencial inclusivo mediante lógicas de abertura da informação. Não obstante, paradoxalmente pode aprofundar as desigualdades por meio de novas exclusões, em face de limites que se apresentam ao acesso às TICs. Distinguem-se desigualdades específicas

fundamental o apoio da Pró-Reitoria de Pós-Graduação e Pesquisa da UFSM, por meio dos programas de bolsas de iniciação científica Fipe, IC-Reuni, Pibic e Pivic, que beneficiaram vários estudantes que participaram em momentos distintos da construção da pesquisa. Participaram do conjunto da coleta de dados: Andressa Costa Prates; Candida Cavalheiro Schwaab, Éder Pandolfo, Fernanda Hack, Fernanda Puhl, Francieli Fão, Luciane Volpatto Rodrigues e Morgana Carniel.

${ }^{7}$ Cf. Mendonça (2012, p. 154): "Pode ocorrer [...] o limite fático da 'reserva do possível’ no momento da concretização de direitos decorrentes da máxima inclusão. Entretanto, não pode o poder público declarar que não é inclusivo (de forma abstrata) por impossibilidade fática, mas tão somente em eventuais impossibilidades reais de concretização de direitos decorrentes [...]. Mas este limite se torna extremamente distante (e só deve ser aceito quando absolutamente impossível) exatamente em decorrência do princípio da máxima inclusão. Ou seja, pela existência do princípio da máxima inclusão, somente pode ser aceito o argumento de reserva do possivel, de impossibilidade fática de um direito decorrente, quando, efetivamente, seja impossível realizá-lo, e, caso este limite apresentado seja financeiro, somente poderá ser considerado se os esforços públicos tiverem sido destinados à concretização máxima possível de todos os direitos decorrentes da cidadania, inclusive o pleiteado, e como frutos de um programa de orçamento participativo.” 
que se combinam e se intensificam reciprocamente, ampliando com isso, a dinâmica das exclusões: desigualdade de acesso; desigualdade de habilidades/aptidões; desigualdade de oportunidades econômicas; desigualdade democrática. ${ }^{8}$ Neste sentido, a exclusão digital constitui novo processo de exclusão social e de limitação à justiça social e ao exercício da cidadania.

Para a supressão dessas desigualdades com o apoio da inclusão digital, investimentos em infraestrutura de redes, equipamentos, alfabetização digital, desenvolvimento de sistemas, softwares e aplicativos adequados às realidades locais, são indispensáveis. $\mathrm{O}$ senso comum constatado no espaço social estudado, no entanto, relaciona a ideia de inclusão digital, quando muito, a pouco além da disponibilização em espaços físicos de computadores para acesso livre e gratuito. Ou seja, não apenas o público em geral, mas mesmo gestores públicos, tomam a inclusão digital tão-somente como o acesso material a dados recursos. Por si só, essa dimensão material não é suficiente à criação das condições para usos cidadãos das TICs; faz-se necessário o seu aspecto cognitivo, para o qual se adota como parâmetro, para a identificação das áreas de maior urgência à efetivação de ações, o Índice de Desenvolvimento Humano (IDH) ${ }^{9}$ ou o Índice de Desenvolvimento Socioeconômico (Idese). Neste sentido, tais índices contribuem à problematização dos estoques de capital cultural em determinada comunidade, região, rede, etc., ou seja, das diferentes configurações de relações espaciais mesmo no interior de determinado município. ${ }^{10}$

${ }^{8}$ Cf. Dijk (2005).

${ }^{9}$ Cassino (2003). Este foi o critério adotado pela Coordenadoria do Governo Eletrônico da Prefeitura de São Paulo para a instalação dos primeiros telecentros naquele município.

${ }^{10}$ Cf. Silveira (2003, p. 31): “[o município é a] unidade fundamental do poder público para a inclusão digital [...], pois a manutenção e o sucesso dos programas de inclusão dependem do convencimento do poder local." 
Em 2014 Frederico Westphalen possuía população estimada em $30.409^{11}$ habitantes. O IDH médio $(0,760)$, em 2010 , fora pouco superior à média dos municípios do Estado do Rio Grande do Sul $(0,746)$; considerados altos. ${ }^{12}$ Não obstante, suas taxas para educação e renda encontram-se em níveis médios (as duas em torno de 0,66) ao aplicar-se o IDESE, ${ }^{13}$ Equivalente, portanto, à média do índice para a educação $(0,654)$, mas bem abaixo da renda $(0,724)$. Com efeito, tendo em conta que cerca de $1 / 3$ da população do município é formalmente ocupada, o valor do rendimento nominal mediano mensal per capita dos domicílios particulares permanentes é pouco expressivo: $\mathrm{R} \$$ 738,33 e R\$ 510,00 para os meios urbano e rural, respectivamente. Aliás, especialmente no meio rural verifica-se acentuada evasão de mão de obra haja vista a faixa etária entre 20 e 29 anos que vive na região ser inferior à média nacional.

Os constrangimentos materiais, associados à distribuição concentrada de capital econômico observados na sociedade frederiquense, dificultam a posse e acumulação de formas de capital cultural na acepção bourdieusiana. ${ }^{14}$ Por efeito, tende também à conservação de mecanismos de impermeabilidade cultural, avessa a investimentos na incorporação de repertórios culturais baseados na diversidade e pluralismo. Esses ao mesmo tempo instigadores de - e instigados por - uso pelos cidadãos das TICs. De fato, ao passo que se encontra no espaço social estudado ênfase ideológica a uma Gesellschaft, sociedade moderna e progressista (aqui em sentido estranho à ideia de desenvolvimento sustentável), observa-se que

\footnotetext{
${ }^{11}$ Fonte: IBGE. Disponível em: <http://cidades.ibge.gov.br/painel/painel.php?codmun= 430850>. Acesso em: 8 out. 2014.

${ }^{12}$ Organização das Nações Unidas (2013).

${ }^{13}$ Fonte: FEE-RS. A faixa considerada média está situada entre os índices 0,599 e 0,699. Disponível em: <http://www.rs.gov.br/conteudo/194550/fundacao-de-economia-eestatistica-divulga-resultados-do-novo-idese/termosbusca=* $>$ Acesso em: 8 out. 2014.

${ }^{14}$ Bourdieu (1979). São três as formas (ou "estados”) do capital cultural: a incorporada, a objetivada e a institucionalizada.
} 
a transição social não consegue romper com a profunda homogeneidade comunitária própria de uma Gemeinschaft: forte coesão social fundada em hierarquias cristalizadas; hegemonia étnica italiana; hegemonia religiosa católica de viés conservador; hegemonia política baseada em bipartidarismo enraizado historicamente (PMDB versus $\mathrm{PP}$ ); patriarcalismo; personalismo; patrimonialismo, etc. Tais fatores de coesão, ao buscarem-se modalidades novas de exercício da cidadania, obrigam à interpelação interventora de instituições transformadoras desse "estado das coisas”. Essas, no entanto, também encontram limites.

Especificamente ao que se tem em tela, políticas públicas de gestão da informação e de investimento à inclusão digital exigem a consideração da existência de desigualdades inter- e intrarregionais, à medida que essas se constituem no contexto de continuidades e descontinuidades. Não obstante, não deixam de existir possibilidades de desenvolvimento abertas às regiões periféricas em face do conhecimento a serviço das regiões, ou seja, o aporte de capital cultural a fim de que a sociedade da informação comporte dimensão de fomento ao desenvolvimento regional. ${ }^{15} \mathrm{Em}$ suma, o capital cultural é fator ao desenvolvimento e, antes de ser o resultado, é condição de possibilidade às políticas públicas de inclusão digital nas regiões periféricas ante a centralidade do Estado brasieiro.

${ }^{15}$ Gálvez (2007, p. 243) enfatiza que "O capital cultural se erige [...] como um dos fatores que dentro de cada região podem marcar uma diferença no processo de desenvolvimento. Neste sentido, o setor da comunicação e da cultura não só apresentam importantes perspectivas de desenvolvimento econômico através de altos efeitos multiplicadores regionais e um forte potencial endógeno, como também se constituem como um vetor de transformação e adaptação tecnológica e social [...].” 


\section{LIMITE INSTITUCIONAL}

Historicamente o fomento de políticas públicas e a tutela do exercício de direitos se configuram, no Brasil, com ascendência da esfera federal que tende a centralizar, embora não exclusivamente, ${ }^{16}$ as diretrizes a serem concretizadas ao uso pelos cidadãos das TICs. A principal referência ao que está em tela é a Secretaria de Inclusão Digital (SID) do Ministério das Comunicações, criada pelo Decreto no 7.462, de 19 de abril de 2011, com o objetivo precípuo da "formulação, execução e articulação de políticas públicas relativas à inclusão digital no âmbito do Governo Federal”. Esse tipo de iniciativa busca uma maior proximidade entre a população e os recursos tecnológicos disponíveis no mercado. O Ministério das Comunicações concebe as políticas de inclusão digital como "ferramentas para o exercício da cidadania” ressaltando que a interação entre indivíduos e TICs é parte integrante do "processo de escolha e de autonomia" individual. Além disso, as TICs também funcionam como recursos que potencializam o capital social nas comunidades de modo a estimular o exercício pleno da cidadania.

A institucionalização da inclusão digital junto ao governo federal resulta de um arcabouço normativo ${ }^{17}$ que veio a lume por meio do Decreto Presidencial de 3 de abril de 2000, que cria o Grupo de Trabalho inter-

\footnotetext{
${ }^{16}$ Subsidiariamente ou por iniciativa própria, verificam-se entidades do terceiro setor e empresas privadas, em geral concentrados em grandes centros urbanos. Destaca-se o Fórum Internacional do Software Livre (Fisl), que acontece anualmente em Porto Alegre, já contando com quinze edições.

${ }^{17}$ A legislação referência da inclusão digital é a seguinte: Decreto № 7.175, de 12 de maio de 2010 (Institui o Programa Nacional de Banda Larga - PNBL); Decreto № 6.948, de 25 de agosto de 2009 (Institui o Comitê Gestor do Programa de Inclusão Digital - CGPID); Decreto № 6.424, de 4 de abril de 2008 (Altera e acresce dispositivos ao Anexo do Decreto no 4.769, de 27 de junho de 2003, que aprova o Plano Geral de Metas para a Universalização do Serviço Telefônico Fixo Comutado prestado no Regime Público - PGMU); Portaria № 13, de $1^{0}$ de outubro de 2012 (Estabelece diretrizes para o funcionamento dos telecentros disponibilizados aos Municípios selecionados por meio do Edital de Chamada Pública № $1 / 2006$, publicado no Diário Oficial da União de $1^{\circ}$ de novembro de 2006 , como parte da
} 
ministerial para examinar e propor políticas e diretrizes além de normas de formas eletrônicas para interação com uma sociedade digital. Em 29 de outubro de 2003, a Presidência da República publicou Decreto, sem numeração, criando oito Comitês Técnicos de Governo Eletrônico e suas atribuições: I - Implementação do Software Livre; II - Inclusão Digital; III - Integração de Sistemas; IV - Sistemas Legados e Licenças de Software; V - Gestão de Sítios e Serviços On-line; VI - Infraestrutura de Rede; VII - Governo para Governo - G2G; e, VIII - Gestão de Conhecimentos e Informação Estratégica. Em 2007 foram divulgadas recomendações técnicas para a construção e adaptação de portais acessíveis para usuários portadores de deficiências auditivas e visuais, a partir de então obrigatórios no âmbito do governo federal.

No mesmo ano de 2007 foi criado o Observatório Nacional de Inclusão Digital (Onid), iniciativa do governo federal em conjunto com a sociedade civil organizada para atuar na coleta, sistematização e disponibilização de informações para o acompanhamento e avaliação das ações de inclusão digital no Brasil. ${ }^{18}$

O Onid, além de ser ferramenta para gestores da inclusão digital, disponibiliza informações detalhadas sobre os telecentros existentes no país. O estabelecimento desses telecentros, embora não seja a única, ${ }^{19}$ tem sido uma das principais ações de fomento à inclusão digital no país.

Política de inclusão Digital do Ministério das Comunicações); Portaria № 16 , de $1^{\underline{o}}$ de novembro de 2012 (Estabelece diretrizes e normas para a execução do Programa Nacional de Apoio à Inclusão Digital nas Comunidades - Telecentros.BR); Portaria no 520, de 27 de dezembro de 2012 (Aprova a Norma geral do Programa Governo Eletrônico - Serviço de Atendimento ao Cidadão - Gesac); Portaria № 13, de $1^{\circ}$ de fevereiro de 2013 (Institui o processo de habilitação e seleção de propostas para o Projeto das Cidades Digitais).

${ }^{18}$ Disponível em: <http://www.governoeletronico.gov.br/o-gov.br/historico-1/historico-1>. Acesso em: 8 out. 2014.

${ }^{19}$ Entre as principais ações e projetos de inclusão digital no âmbito do governo federal, destacam-se: Banda Larga nas Escolas; Casa Brasil; Centros de Recondicionamento de Computadores; (CRCs); Cidades Digitais; Computadores para Inclusão; Inclusão Digital da Juventude Rural; Oficina para Inclusão Digital; Projeto Cidadão Conectado - Computador 
A observância de diretrizes orienta a efetivação e desenvolvimento das atividades nos telecentros: inclusão digital como direito de cidadania; pluralidade de modelos sob mesmas diretrizes; segmentação de públicos; infraestrutura; comprometimento com o desenvolvimento local; integração; avaliação; e utilização de software livre. A fim de participarem do Programa Nacional de Apoio à Inclusão Digital nas Comunidades (Telecentros.BR), os órgãos públicos e as entidades da sociedade civil devem observar o seguinte fluxo de apresentação de propostas:

Figura 1 - Fluxo de apresentação de propostas ao Telecentros.BR ${ }^{20}$

\section{Seleção de Propostas Aderentes}

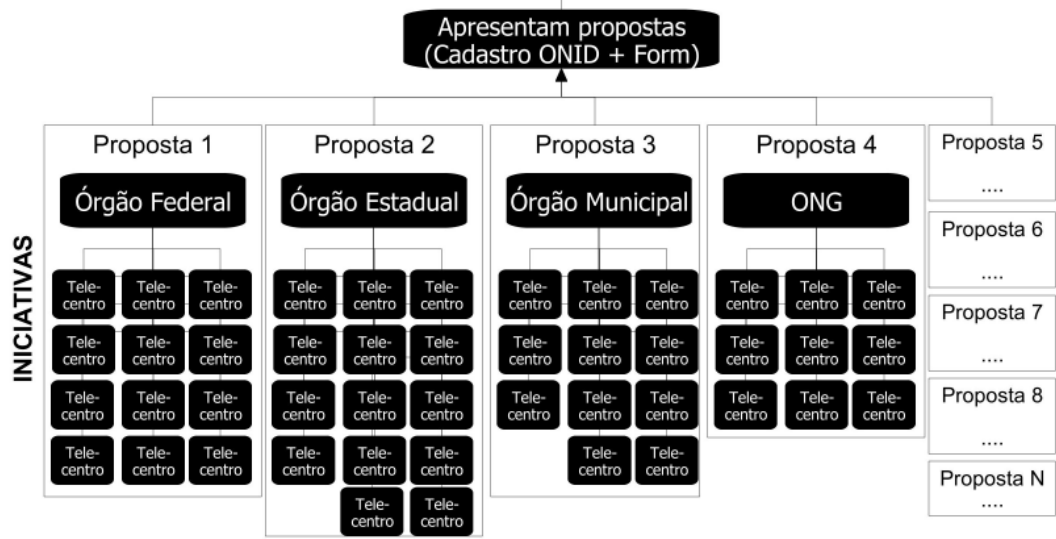

O programa oferta equipamentos de informática e de conectividade, bem como bolsas e formação dos bolsistas da comunidade na faixa etária de 16 a 29 anos, que serão monitores dos telecentros. Em contrapartida,

para Todos; Programa de Implantação de Salas de Recursos Multifuncionais; Programa de Inclusão Social e Digital;Redes Digitais da Cidadania; Telecentros; Territórios Digitais; Um Computador por Aluno.

${ }^{20}$ Fonte: Proposta preliminar do Programa Telecentros.BR, apresentada sob a denominação "Projeto Nacional de Apoio a Telecentros" em audiência pública e em consulta pública realizadas entre maio e junho de 2009. 
o proponente deve dispor de espaço físico adequado e acessível (com, no mínimo, $48 \mathrm{~m}^{2}$ de área disponível, caso solicite kit de equipamentos novos); rede elétrica interna adequada; manutenção de energia elétrica, limpeza, segurança e conservação básica dos equipamentos de informática do telecentro. Para telecentros que não demandam kit de equipamentos novos: mobiliário; rede lógica (interliga computadores ao servidor); atendimento às diretrizes; ${ }^{21}$ acompanhamento pela entidade proponente e prestação de informações à Coordenação Executiva do programa de maneira continuada.

Apesar do grau de abrangência da política federal da inclusão digital, a participação do município de Frederico Westphalen é bastante limitada e recente, restringindo-se a três ações: 1) Contrato $\mathrm{n}^{0}$ 190/2014 da Prefeitura com o Serviço Nacional de Aprendizagem Comercial (Senac) para realização de cursos profissionalizantes a serem promovidos pela Secretaria de Assistência Social e Habitação em atendimento a famílias cadastradas que recebem o beneficio do Programa Bolsa Família e do Cartão Mais;;2 2) Lei Municipal nº 4.094/2014 que institui termo de cooperação com a Cooperativa de Crédito Rural com Interação Solidária

${ }^{21}$ As diretrizes específicas do programa são: ter as portas abertas ao uso por todo cidadão; não cobrar pelo uso dos recursos providos pelo Programa; montar um Conselho Local, representativo de comunidade, equipe e usuários; estar aberto ao menos 30 horas semanais, em horários compatíveis com a comunidade (regra definida pelo Conselho Local); oferecer à população atividades múltiplas, incluindo acesso livre assistido, cursos e projetos de desenvolvimento local; permitir acesso a ferramentas web 2.0 e à evolução da web/internet; manter ao menos um monitor (agente local de inclusão digital); manter registro atualizado de usuários/atendimentos; indicar entidade local à qual o telecentro se reporta, que deve ser de natureza pública, ou privada sem finalidade de lucro; se instalado em escola pública, participar do programa Escola Aberta (MEC) ou similar; caso recebam equipamento de informática do Programa, mantê-los configurados com sistemas operacionais e aplicativos (softwares) livres.

${ }^{22}$ Os cursos considerados como de "inclusão digital" são dois: "Curso de fotografia digital com Photoshop": princípios de fotografia, cores, introdução à fotografia digital, profundidade de campos, flash, arquivos, ambiente de trabalho do Photoshop e sua configuração, caixa de ferramentas, ajuste de imagens, seleções, camadas e efeitos visuais. Carga horária de 30 horas e "Curso de informática empresarial": utilização do Windows, Excel e Power Point. 
(Cresol), que autoriza o município a disponibilizar espaço físico e equipamentos de informática na sede do Centro de Referência de Assistência Social (Cras) e à Cresol, e de nele disponibilizar monitor para ministrar aulas semanalmente, em dias e turnos variados, com o objetivo de familiarizar os participantes com os computadores e a Internet; ${ }^{23} 3$ ) Termo de adesão, assinado em novembro de 2011, ao Programa Nacional de Acesso ao Ensino Técnico e Emprego (Pronatec - Bolsa-Formação Trabalhador), no âmbito do Plano Brasil Sem Miséria, cujos destinatários prioritários são os beneficiários de programas federais de transferência de renda.

Constata-se que a iniciativa mais longeva data de 2011 e que o enfoque é a qualificação de mão de obra visando o aumento da produtividade junto a segmentos de baixa escolaridade. Antes disso, verificavam-se - e ainda se verificam - disciplinas de introdução à informática nas escolas públicas. Os professores/monitores de regra são comissionados (cargos de confiança/funções gratificadas). Isto é, em caso de derrota eleitoral do partido do mandatário municipal nas eleições majoritárias, esses educadores são os primeiros a perder o vínculo à rede de ensino, acarretando o encerramento, ao menos temporário, das aulas de informática, o mais próximo do que se poderia considerar como ação de inclusão digital. ${ }^{24}$

Efeito dessa dinâmica conservadora é a limitada proficiência dos servidores das escolas em recursos básicos de informática. Ao serem atribuídas notas, em escala crescente de conhecimento (de 1 a 5), a pesquisa realizada junto a professores e funcionários obteve os resultados aferíveis por meio dos seguintes gráficos:

\footnotetext{
${ }^{23}$ As aulas integram os projetos "Na Cresol as Mulheres Cooperam" e "Na Cresol a Melhor Idade Coopera".

${ }^{24} \mathrm{~A}$ última vez que isso ocorreu foi em 2012, em que o candidato a prefeito do PMDB foi derrotado pelo do PP na disputa eleitoral.
} 
Gráficos 1 e 2 - Proficiência dos servidores das escolas na utilização de editores de texto

\section{Editor de Texto (software proprietário)}

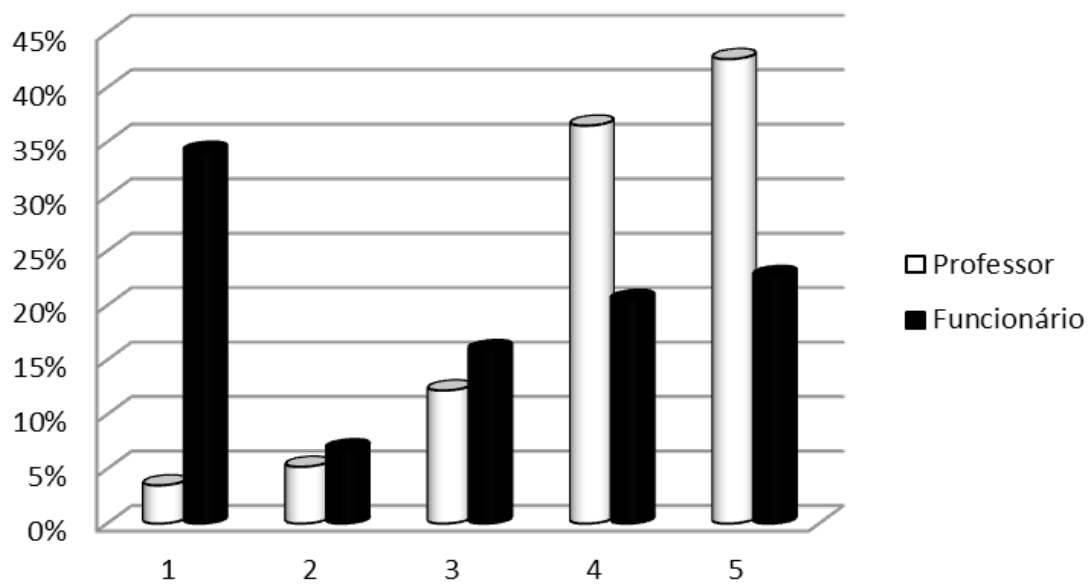

Editor de Texto (software livre)

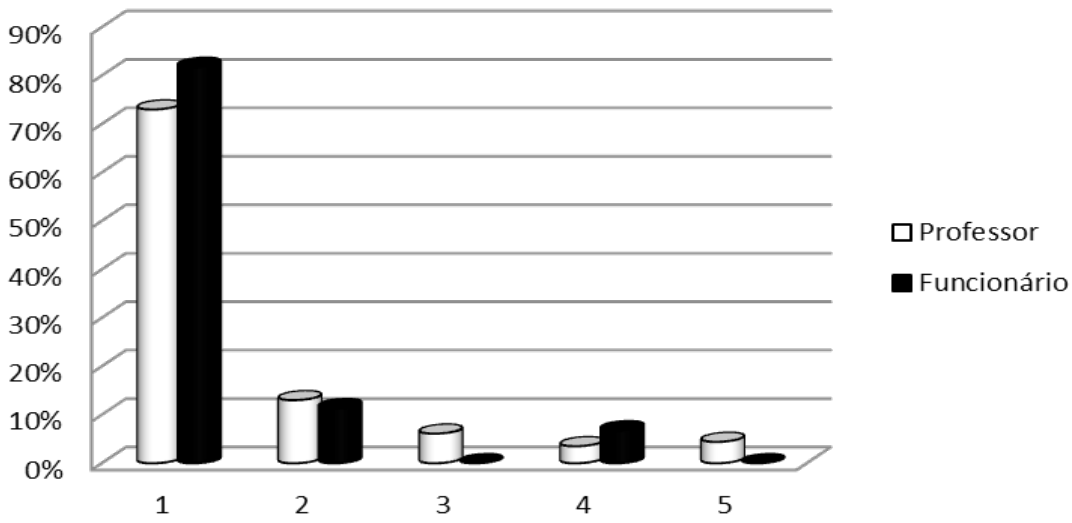

Os editores de texto supra, Word e BrOffice/LibreOffice (softwares proprietário e livre, respectivamente) são considerados imprescindíveis, em especial aos professores, que precisam redigir as mais variadas atividades aos estudantes. A seguir, verificam-se os resultados para a proficiência 
no editor de apresentações Power Point, muito utilizado em palestras e salas de aula, e do editor de planilhas Excel, ferramenta empregada para cálculos e para construção de gráficos. Ambos softwares proprietários. ${ }^{25}$

Gráficos 3 e 4 - Proficiência em editores de apresentações e de planilhas

Editor de Apresentações (software proprietário)

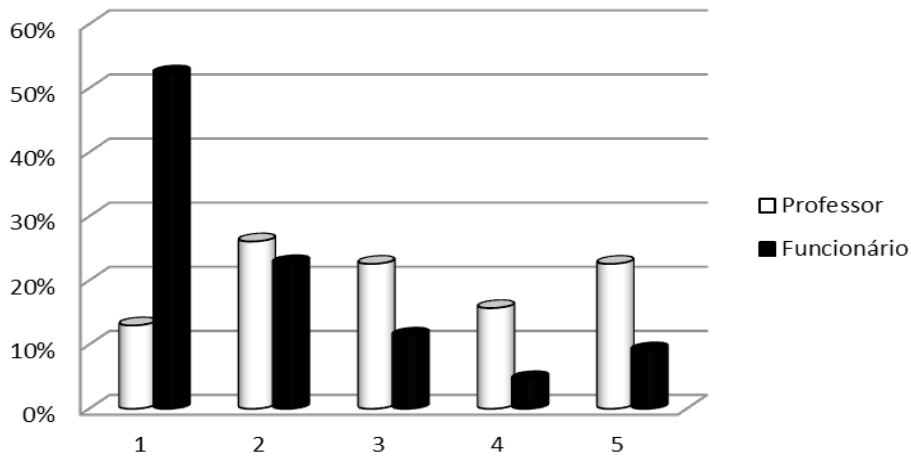

Editor de Planilhas (software proprietário)

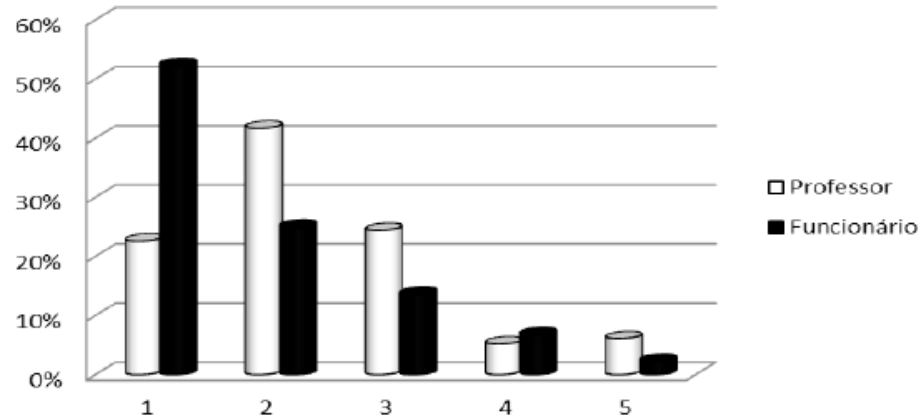

${ }^{25}$ Foram adotados esses softwares no levantamento estatístico em razão de que, de modo similar ao uso de navegadores (browsers), são considerados recursos básicos a serem observados para aferir-se à proficiência ou alfabetização digital. Em tempo, em relação ao uso de navegadores, os servidores das escolas conheciam apenas o Internet Explorer (IE) e o Google Chrome (GC). Em relação à proficiência no uso desses softwares, ao atribuírem a nota 5 (máxima), os porcentuais foram os seguintes: $\mathrm{IE}=42,6 \%$ e $25 \%$ para o nível de conhecimento de professores e funcionários, respectivamente; $\mathrm{GC}=25,2 \%$ e $13,6 \%$, idem, respectivamente. 
Deduz-se que tanto professores quanto funcionários das escolas de Frederico Westphalen apresentam baixa proficiência em conhecimentos básicos de informática no que se reporta à utilização de softwares amplamente disseminados. Essa limitação dos servidores, entre outros fatores, pode vir a indicar obstáculos também à proficiência dos estudantes, mesmo que haja aulas e laboratórios de informática na maioria das escolas do município. De fato, ao aplicar-se a escala crescente de 1 a 5 para o grau de conhecimento em softwares/aplicativos, foram obtidos os seguintes resultados junto aos 196 estudantes entrevistados:

Tabela 1 - Proficiência dos estudantes em diferentes softwares

\begin{tabular}{|c|c|c|c|c|c|c|c|}
\hline \multirow{2}{*}{ CATEGORIAS } & \multirow{2}{*}{ NOMES } & \multicolumn{5}{|c|}{ ESCALA } & \multirow{2}{*}{ TOTAL } \\
\cline { 2 - 8 } & & 1 & 2 & 3 & 4 & 5 & \\
\hline Compactador & WinZip & 161 & 18 & 8 & 4 & 5 & 196 \\
\hline Ed. Apresentações & Power Point & 95 & 17 & 25 & 24 & 35 & 196 \\
\hline \multirow{2}{*}{ Editores de Áudio } & Nero & 105 & 30 & 18 & 26 & 17 & 196 \\
\cline { 2 - 8 } & Audacity & 181 & 8 & 5 & 1 & 1 & 196 \\
\hline \multirow{2}{*}{ Editores de Blogs } & Wordpress & 146 & 26 & 13 & 8 & 3 & 196 \\
\cline { 2 - 8 } & Blogspot & 148 & 24 & 14 & 7 & 3 & 196 \\
\hline Editor de Imagens & MovieMaker & 137 & 17 & 14 & 13 & 15 & 196 \\
\hline Editor de Planilhas & Excel & 116 & 34 & 20 & 12 & 14 & 196 \\
\hline \multirow{2}{*}{ Editores de Texto } & Word & 82 & 14 & 26 & 30 & 44 & 196 \\
\cline { 2 - 8 } & BrOffice/Libreoffice & 164 & 9 & 7 & 8 & 8 & 196 \\
\cline { 2 - 8 } & GoogleDocs & 145 & 29 & 11 & 5 & 6 & 196 \\
\hline \multirow{2}{*}{ Navegadores } & Internet Explorer & 57 & 17 & 27 & 31 & 64 & 196 \\
\cline { 2 - 8 } & Google Chrome & 80 & 6 & 11 & 17 & 82 & 196 \\
\cline { 2 - 8 } & Mozilla Firefox & 96 & 21 & 18 & 20 & 41 & 196 \\
\hline
\end{tabular}

Em tempo, nessas Tabelas levam-se em conta apenas a competência técnica ou o uso instrumental das TICs. Não se adentra na questão dos usos cidadãos expressos ou subjacentes às políticas públicas para inclusão digital. De toda sorte, tão ou mais importantes que o limite institucional é o limite disposicional que deve enfrentar essa comunidade diante da transição social. 


\section{LIMITE DISPOSICIONAL}

Poder empreender usos cidadãos às tecnologias depende de disposições, ${ }^{26}$ e modalidades de predisposições que desempenham papel fundamental a partir da primeira interiorização de visões de mundo decorrente de experiências práticas na família e na escola, por meio de palavras, gestos, objetos e ações. Essas disposições, por óbvio, não engendram comportamentos inexoráveis: atualizam-se em razão das diferentes situações em que o pretenso cidadão se depara em seu itinerário, permanecendo assim, o princípio de seleção das manifestações que produzir ou julgar. Ou seja, no processo social elaboram-se estruturas cognitivas por meio das quais os sujeitos obtêm o conhecimento prático do mundo social, cujo sentido comum torna possível a elaboração de um mundo comum e sensato, que deve ser entendido como uma matriz de disposições, isto é, de percepções, apreciações e ações, adquiridas por intermédio das experiências sociais inculcadas.

Considerando que as disposições são princípios geradores de práticas objetivamente classificáveis, foram formuladas hipóteses de investigação ao presente trabalho. Na pesquisa de campo observaram-se práticas culturais que propiciaram descrições etnológicas e levantamentos estatísticos. As análises buscam avaliar as articulações processadas em um espaço tridimensional: vertical, que avalia os capitais econômico, cultural etc.; estrutural, que opõe, no interior de uma mesma esfera social, o capital

\footnotetext{
${ }^{26} \mathrm{Ou}$, noutros termos, habitus. Cf. Bourdieu (1980, p. 88-89): “Os condicionamentos associados a uma classe particular de existência produzem habitus, sistemas de disposição duráveis e transponíveis, estruturas estruturadas dispostas a funcionar como estruturas estruturantes, quer dizer, como princípios geradores e organizadores de práticas e de representações que podem ser objetivamente adaptados a seu objetivo sem supor o intuito consciente de fins e o domínio expresso das operações necessárias para lhes alcançar [...]."
} 
econômico e o capital cultural; e, por último, a dimensão da trajetória que possibilita a interpretação da Antiguidade na posse desse capital econômico/cultural.

Como pressuposto, um agrupamento (ou um indivíduo), quando se propõe a fazer uso de um meio técnico, já está predisposto a determinados perfis do que se faz ou do que se pode fazer, isto é, daquilo que é realizável para este contingente social. A limitação social que pesa sobre a técnica dá-se então bem menos pelos limites do dispositivo técnico, quer dizer, suas possibilidades técnicas, do que pelos modelos implícitos que lhe definem e que são assimilados pelas práticas interiorizadas. Nesse sentido, um grande número de entrevistados afirmou que aprendeu a usar o computador de modo autodidata, na prática ou com o auxílio de amigos ou parentes; nem todos fazem/fizeram curso de informática. Sobre os conteúdos acessados, verificou-se que os estudantes mais acessam mídias sociais digitais (popularmente conhecidas como "redes sociais"), fazendo uso de ferramentas de bate-papo. Por desconhecerem as funcionalidades de certos softwares, não sabendo associar o nome à função desempenhada pelo programa, alguns se envergonhavam e outros inventavam respostas. Embora a maioria das crianças e adolescentes (52,6\%) respondesse que usam as TICs para fins de estudo e pesquisa, a porcentagem de acessos a jogos chega a $51,5 \%$ e às mídias sociais $64,8 \%$. De acordo com os entrevistados, os jogos por eles utilizados são desprovidos de conteúdo educativo. Não obstante, as crianças das séries iniciais são instigadas a brincar com jogos de entretenimento com o intuito de ambientarem-se com o uso dos computadores.

Constata-se que o uso da internet se dá em casa, por meio de computador desktop ou de notebook. Não adquirem relevo, portanto, em Frederico Westphalen, as políticas públicas de inclusão digital. Ademais, os usos das TICs estão distantes de representar propostas ao incremento da cidadania. 
Tabela 2 - Local de acesso à internet

\begin{tabular}{|c|c|c|c|c|c|c|c|c|c|}
\hline $\begin{array}{c}\text { Em } \\
\text { casa }\end{array}$ & $\begin{array}{c}\text { Em local } \\
\text { público }\end{array}$ & $\begin{array}{c}\text { Na } \\
\text { escola/ } \\
\text { Trabalho }\end{array}$ & $\begin{array}{c}\text { Na casa de } \\
\text { um amigo/ } \\
\text { vizinho/ } \\
\text { parente }\end{array}$ & $\begin{array}{c}\text { Em lan } \\
\text { house }\end{array}$ & $\begin{array}{c}\text { Em } \\
\text { tele- } \\
\text { centro }\end{array}$ & Outro & $\begin{array}{c}\text { Não } \\
\text { acessa } \\
\text { a } \\
\text { Internet }\end{array}$ & $\begin{array}{c}\text { NS/ } \\
\text { NR }\end{array}$ & TOTAL \\
\hline 133 & 1 & 28 & 15 & 0 & 1 & 6 & 11 & 1 & 196 \\
\hline
\end{tabular}

Em suma, são os porcentuais verificados junto aos estudantes respondentes 1) sobre o grau de conhecimento ao usos das TICs: $2 \%$ nenhum; $1 \%$ pouco; $10 \%$ razoável; $45 \%$ médio; $24 \%$ bastante; $1 \%$ domina as técnicas; $1 \%$ não sabe ou não respondeu (NS/NR); 2) a aquisição desse conhecimento foi por meio de: $32 \%$ amigo/parente/vizinho; $30 \%$ de modo autodidata; $16 \%$ curso pago de informática; $11 \%$ aulas de informática da escola; $10 \%$ projeto promovido pela Prefeitura ou outro órgão público; $1 \%$ NS/NR; 3) sobre a finalidade do uso: 25\% estudos/pesquisas escolares; $20 \%$ entretenimento em geral; $20 \%$ jogos; $18 \%$ comunicação com parentes/ amigos; $8 \%$ downloads; $5 \%$ blogar; $3 \%$ outros; $1 \%$ NS/NR. Isto é, reiterando, pouco se constata a proeminência de espaços públicos como referência para uso e aquisição de conteúdos formativos ao exercício da cidadania de máxima inclusão.

\section{CONSIDERAÇÕES FINAIS: EFETIVAÇÃO DE DIREITOS PARA A EDUCAÇÃO (DIGITAL)}

O estudo constatou que não existe uma eficaz concretização de direitos a uso pelos cidadãos das TICs, em especial a internet, em Frederico Westphalen. Não há suficiente interação entre a esfera de poder municipal e o governo federal, centro difusor das principais políticas públicas de inclusão digital. Não obstante, mesmo que se consiga em algum momento superar essa escassa articulação institucional, ela por si só não basta para romper com a mera lógica de formação de mão de obra barata mais produtiva. Para transcendê-la, de início é necessária a superação dos 
limites socioculturais, institucionais e, talvez o mais complexo, disposicionais. Para tanto, a viabilidade ao exercício pleno da cidadania depende do desenvolvimento qualitativo da democracia no território do município, constituindo espaços de discussão e de deliberação que possam transcender ao que oferta a democracia formal praticada pouco além dos pleitos eleitorais. Por derradeiro e de modo fundamental, como atenta Paulo Freire,${ }^{27}$ as sociedades que vivem a transição de uma época a outra, ante a rapidez e flexibilidade desse processo social, também devem desenvolver a formação e o desenvolvimento de um espírito flexível a fim de tornar possível a integração humana. Assim, na perspectiva do direito a integrar-se a uma sociedade que rapidamente se transforma, junto com a alfabetização/ educação digital, aprofunda-se, o que conclui a investigação, a consciência da urgência e prioridade à qualificação da educação básica das crianças e de suas famílias, com conteúdos curriculares que contemplem a diversidade, o pluralismo e a complexidade do mundo contemporâneo.

\section{REFERÊNCIAS}

ALEXY, Robert. Teoria dos Direitos Fundamentais. Trad. Virgílio Afonso da Silva. São Paulo: Malheiros, 2008.

BABBIE, Earl. Métodos de pesquisa de Survey. Trad. Guilherme Cezarino. Belo Horizonte: Editora UFMG, 2001.

BOURDIEU, Pierre. Les Trois États du Capital Culturel. Actes de la Recherche en Sciences Sociales. L’institution scolaire. Vol. 30, nov.1979. p. 3-6. . Le Sens Pratique. Paris: Minuit, 1980.

BUBER, Martin. Sobre comunidade. São Paulo: Perspectiva, 2008.

${ }^{27}$ Cf. “A Sociedade Brasileira em Transição”. In: FREIRE (1967, p. 39 et seq.). 
CASSINO, João. Cidadania digital: os telecentros do município de São Paulo. In: SILVEIRA, Sérgio Amadeu da; CASSINO, João. Software Livre e Inclusão Digital. São Paulo: Conrad, 2003. p. 49-62.

CAZELOTO, Edilson. Inclusão digital. Uma visão crítica. São Paulo: Editora Senac, 2008.

DIJK, Jan A. G. M. van. The Deepening Divide. Inequality in the Information Society. London: Sage, 2005.

FREIRE, Paulo. Educação como prática da liberdade. Rio de Janeiro: Paz e Terra, 1967.

GÁLVEZ, Francisco J. M. Políticas de comunicação e desenvolvimento regional. Desafios diante da sociedade do conhecimento. In: RAMOS, Murilo César; SANTOS, Suzy dos (Orgs.). Políticas de comunicação - buscas teóricas e práticas. São Paulo: Paulus, 2007. p. 235-258.

MIRANDA, Luciano. Usos da Internet, Redes Sociais e Inclusão Digital (Projeto de Pesquisa). Santa Maria: Universidade Federal de Santa Maria, 2014.

MENDONÇA, Felippe. A evolução do conceito jurídico de cidadania no panorama democrático do século XXI. 2012. Dissertação (Mestrado) - Faculdade de Direito da Universidade de São Paulo, São Paulo, 2012.

OLIVEIRA, Rafael Santos de; RODEGHERI, Letícia Bodanese. A utilização da internet e a construção da ciberdemocracia no Brasil. In: Mídias e direitos da sociedade em rede. Ijuí: Ed. Unijuí, 2014. p. 199-225.

ORGANIZAÇÃO DAS NAÇÕES UNIDAS. ONU. Atlas Brasil 2013. Programa das Nações Unidas para o Desenvolvimento, 2013.

SILVEIRA, Sérgio Amadeu da; CASSINO, João. Software livre e inclusão digital. São Paulo: Conrad, 2003.

WOLKMER, Antonio Carlos. Novos pressupostos para a temática dos direitos humanos. In: RÚBIO, David Sanchez; FLORES, Joaquín Herrera; CARVALHO, Salo de (Orgs.). Direitos humanos e globalização. Fundamentos e possibilidades desde a teoria crítica. 2. ed. Porto Alegre: Edipucrs, 2010. p. 14-29.

Recebido em: 28/5/2015

Aceito em: 15/6/2015 